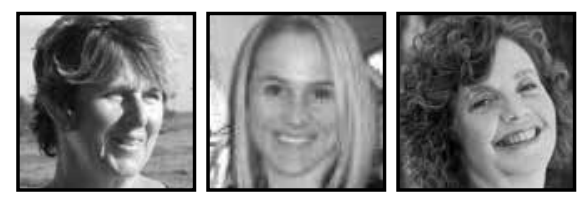

\title{
Bridging the Gap: Teacher-Parent Partnerships for Students With Autism Spectrum Disorder
}

Teri A. Todd, California State University, Northridge Jennifer Beamer, Oregon State University Joan Goodreau, Rowland Unified School District

\section{ABSTRACT}

There are increasing demands on the education system to meet the needs of students with autism spectrum disorder and the requests of their parents. Teacherparent partnerships may be one avenue to improve services, however teachers often feel unprepared and lack strategies and skills to effectively engage parents. This multilayered article presents a story from a teacher who is a parent of a student with ASD. It is followed by a discussion of the state of teacher preparation programs and barriers that impede successful partnerships. Suggestions for improving partnerships are included.

\section{Bridging the Gap}

Teacher-Parent Partnerships for Students With Autism Spectrum Disorder

eachers are highly educated professionals, completing demanding
university degrees and accreditations. They are ready and willing to be
classroom managers, deliver individualized instruction, coordinate a variety of specialists, and do so with enthusiasm and passion. But are they truly prepared for all special education has in store? 
Research on the quality of education and teacher preparation programs has been going on for the past 30 years (Unal \& Unal, 2014), and has consistently shown that teachers feel unprepared to work with parents. Unfortunately, the results of the research have not manifested into large improvements of the situation. Today's teachers still report feeling unprepared to meet the challenges of children with autism spectrum disorder (ASD). It is not surprising that parents and other stakeholders express low levels of confidence in the abilities of special education teachers (Tincani, Cucchiarra, Thurman, Snyder, \& McCarthy, 2014). As the reported number of children with ASD increase (Frieden, Joffe, Cono, Richards, \& lademarco, 2014), school administrators and teachers will be challenged to effectively serve this growing population. One source of expertise, and also tension, may be parental involvement. In an effort to present different perspectives, this article opens with the voice of a teacher (Teri Todd) who is also a parent of a child on the autism spectrum. A discussion pertaining to information on teacher preparation and ASD, tensions experienced by teachers and parents, along with suggestions for next steps will follow.

\section{A Teacher's Story}

As a parent of a son with ASD and an educator, I learned we cannot see the whole picture in Special Education. We need to change our point of view and see the challenges from different perspectives.

When I was a Special Education teacher, I sometimes became frustrated with parents who could not come to meetings or follow up with homework. But when I took off my Special Education teacher glasses and put on my parent point of view, I had a better understanding of their challenges and struggles. My parent story about lan and his preschool teacher happened decades ago, but I always recall it in the present.

It happened 30 years ago during a cold Canadian winter when my three-year-old son had just been diagnosed with ASD. As a single mother, I had a hard time finding childcare, and when a teacher called about ways to help lan, I was too much in a daze to listen. The story went like this:

My car refuses to start in the sub-zero weather. I pound on the steering wheel and beg my old Chevy to start. But my car won't listen. It has heard my pleas before. I walk inside my house to call my son's teacher. I stare at the phone and rock in my chair the way lan rocks back and forth in his bed. I don't want to tell her that I can't make the conference, but I must call before lan gets back from school. No one talks on the phone with lan around. 
"I'm sorry Mrs. Browen, the car will not start and I can't make it today, but is there something I can do with lan at home?"

"Ian will learn his colors much faster if he practices a sorting game with you at home," Mrs. Browen says.

"I want to follow up with what you do at school, Mrs. Browen. Thanks to you, lan's starting to follow directions and doesn't hit himself as much."

"Many parents don't know where to begin to help their kids, so I'm happy you are going to work with lan." Her voice sounds soft yet firm, just the way it does when she talks with her kids in class.

I jump out of my chair as soon as I hang up. My old teaching credential would come in handy after all. Who cares if I don't have money to fix my broken car? Now, I can help fix lan. This will be easy, right? I take a deep breath and look for the construction paper and cupcake pan Mrs. Browen says I need for lan's classifying game. I open kitchen cupboards and pots and pans explode with a crash around my feet. I peer into the dark cave. Where's the pan? I saw it the last time I baked cupcakes and try to remember when I had last baked. Last Christmas? lan's first birthday? I hunt for the pan and construction paper in my girls' rooms, but all I find is crumpled brown and grey paper along with an empty crayon box.

I plan to take the bus and go shopping this weekend with my girls, so they can help me with lan. He is three, does not talk or go to the bathroom, so if he doesn't know his colors, what does a few more days matter? But by the weekend, lan's nose is running as hard as the snow outside.

A few days later, the phone rings and Mrs. Browen asks, "How is lan getting along with his colors?"

"Great," | lie.

"Well it always shows when parents help at home," she says.

What did she mean by that? Can she hear the lie in my voice? I vow to get to the supermarket next weekend, even if I have to walk there pulling lan in the sled. I had worked with a hundred kids when I taught school. So of course I can teach lan, I think, can't I? The broken car, a snowstorm, lan's cold - these aren't my fault are they? 
The next Saturday, my ten-year-old daughter, Monica, lan, and I take the bus to the supermarket. Monica pushes lan, who makes bus noises while in the stroller, down the aisles. We have a short timeline to shop before lan wants to go home. So we grab bread and milk, along with a cupcake tin, and rush to an open register next to rows of candy bars. lan stops rocking his head back and forth and snatches a Hershey Bar. I grab his hand, pry the chocolate from his fist and toss it on the counter just out of his reach. His face opens into a pit where a trapped animal howls.

lan's shrieks hurry the cashier, who rings up the groceries. The people in the other lines just want the screaming to stop, too. They mutter under their breath, "Look at that spoiled brat."

I prefer spoiled brat to autistic. At least brat is in the range of normal. Monica looks up and says, "Everyone's looking at us, let's get out of here."

By the time we make it home and put lan to bed, I am too tired to cut the construction paper squares for the game. But when lan wakes, I can't put it off any longer. I set the cupcake tin with different colors in each hole on the table and sit him in his booster chair beside me. I hand him a yellow square. He puts in his mouth. I retrieve the wad and hand him another square. lan screams and throws it. He kicks his feet against the table, and the cupcake tin crashes to the floor with the squares scattering like confetti.

Just then, Monica comes back from a friend's house and says, "Hey Mom, what's up? You look beat."

I point to the jumbled paper squares and tin on the table. "He won't match colors."

"Oh yeah, he will," she says and grabs him and tickles his belly. She has the same intense look as she does when I give lan bad tasting medicine. The oldest of our family, she believes that sometimes you have to do things you don't want to do for your own good, especially if you are her little brother or sister.

They go back to sit at the kitchen table. lan starts to cry, and Monica puts a square into lan's hand. Then with her hand over his hand she puts the squished red square into the red hole in the tin.

She laughs and says, "good boy." Monica doesn't mind his crying. She has heard crying since she was two years old when we brought her little sister, Jennifer home from the hospital. To her, tears are just part of the job that includes changing diapers, naptimes, and spooning down pureed beets. 
"Show me green," says Monica, and this time he matches the color the first time she tells him.

"Good job!" I yell and clap the way I do at Monica's soccer matches. "He can do it," I say to Monica.

"Sure, you have to do it fast to keep his attention and you just have to stick with it," she says with all the authority of the eldest child.

"Yes, now let me do it," I say and slide into the chair on the other side of lan. "Show me red, Ian."

He matches the five remaining colors and I hug him and Monica. Why does my ten-yearold daughter have to show me how? Then I remember another teacher in my old school telling me that it was easier to teach a whole classroom than your own child.

The following Wednesday, Mrs. Browen asks over the telephone, "How's it going?"

"Oh lan is matching his colors, he can put the colored squares into the correct hole in the cupcake tin,"I say.

"That's great. Once you finally got started, he caught on fast."

How can she know? I want to ask, but all I say is, "Yes there's nothing to it really. You just have to stick with it."

The key point in my story is that lan's teacher, Mrs. Browen, understood I had difficulties at home, as I had shared some of my struggles with her. She was not negative or judgmental. She encouraged any small steps I took and let me take my time. Teachers, like Mrs. Browen, are the crucial component in student success and parent growth.

When I became a District Program Specialist, I had to change my perspective again and appreciate both the professional and parent view. The challenge is to balance parent expectations for their child with the reality of the classroom. Special Education teachers face time constraints, IEP requirements, curriculum demands, limited resources and large classes, which all can interfere with a teacher's empathy of what parents face at home.

Parents also see their problems from their own standpoint and sometimes make unrealistic demands on teachers. The only way to bring these two viewpoints together is 
for parents and teachers to become aware of each other's problems and work together. Teacher preparation programs may be a vital staging ground to begin to bridge the gap between parents and teachers. However as will be discussed, teacher development is complex, and there remain many challenges as the field struggles to keep up with the demand.

\section{Teacher Preparation}

Special education services throughout North America have evolved over the last two decades. As people with disabilities are no longer routinely institutionalized, the conditions and characteristics of various disabilities and accompanying individual educational needs have gained both understanding and acceptance within the public and political environment. The following discussion will utilize statistics and policy based mostly on United States' observations. However, it is our belief that concerns regarding inclusion of students with disabilities are not unique to this country (Hutchinson, 2006; Leblanc, Richardson, \& Burns, 2009; Winzer, 2007). Therefore, we will use a perspective that should be interpreted from a North American lens, which has been informed by research, practice, and policy based mostly in the United States.

Under the Individuals with Disabilities Education Act (IDEA), elementary and secondary special education teachers are required to be "highly qualified." The definition of "highly qualified," within IDEA, closely aligns with the Elementary and Secondary Education Act, and requires highly qualified teachers to: 1) have a bachelor's degree, 2) have full state certification or licensure, and 3) demonstrate subject-matter knowledge for the subjects they teach. While reports indicate that almost $90 \%$ of special education teachers are "highly qualified," there is a considerable shortage of teachers qualified to serve students with emotional disturbance/behavioral disorders and ASD (Institute of Education Sciences, U.S. Department of Education, 2011). In particular, $46 \%$ of districts routinely experience difficulty finding qualified applicants to serve students with ASD.

Special education teachers are charged with a multitude of responsibilities that are arguably unique from general education teachers. By nature, students with disabilities are unique and require individualized instruction, as evidenced by the Individuals With Disabilities Education Act (IDEA, 2004). In the US, approximately $13 \%$ of the student population are receiving special education services, and nearly half a million of those served have been diagnosed with ASD (U.S. Department of Education, National Center for Education Statistics, 2013). Furthermore, as with all students with disabilities, students with ASD spend varying amounts of time in different educational placements. The latest figures estimated that in the US, in $2011,39 \%$ of students with ASD spent $80 \%$ 
or more of their school day in the general class; $18.2 \%$ spent between $40 \%$ and $79 \%$ in the general class; and $33.7 \%$ spent less than $40 \%$ in the general class. Additionally, 9.1\% of students with ASD were served in separate facilities or residential programs (U.S. Department of Education Institute of Education Sciences National Center for Education Statistics, 2013). In Canada, the distribution of students with ASD in various class settings is less clear. However, it is likely that there is a similar picture to that of US classroom settings, as 55\% of Canadian students with disabilities attend regular classes in the regular school setting (Kohen, Uppal, Khan, \& Visentin, 2006). Considering the unique qualities of individuals with ASD, along with their varying educational needs, it is clear that special educators need training to work with students across a wide range of service delivery systems.

\section{Teacher Preparation Programs and ASD}

As the number of students being identified on the autism spectrum rises, so does concern regarding teacher preparation. While early reports indicate that special education teachers were not prepared to work with students with ASD (Schopler \& Olley, 1980), the issue has been revisited with calls for more specific training of teachers and service providers who have autism-specific knowledge (Simpson, 1995, 2003 , 2004). However, with the call for specialized training comes a particular dilemma as the field of special education training has trended towards models that include a non-categorical and cross-categorical approach. While non-categorical approaches are helpful in moving away from the medical model and focusing on the individual needs of each student, this has not translated into better education in the eyes of stakeholders. As the number of children with ASD continues to increase and become one of the largest groups of students with differing abilities in the school system, institutes of higher education (IHEs) will have to evaluate this approach. Of particular concern is the lack of scope and depth of many training models within preparation programs. In fact, personnel preparation has been highlighted as "one of the weakest elements of effective programming for children with autistic spectrum disorders and their families" (National Research Council, 2001, p. 225).

While over a decade has passed since the National Research Council's (NRC, 2001) published recommendations for educating students with ASD, it appears that concerns regarding personnel training remain. While it is clear that training efforts are in place and that programs directed toward serving students with ASD exist, researchers have also provided evidence that many stakeholders are not confident in the efficacy of these efforts. 
A recent study by Tincani and colleagues (Tincani et al., 2014) examined NRC's recommendations and investigated if they were accepted and perceived as valid by consumers. The researchers also looked into the degree to which the recommendations have been implemented. With 149 parent respondents and administrators from 35 different state educational agencies, the results indicated that while parents and administrators were in general agreement with the NRC recommendations, implementation of these recommendations are perceived as poor to moderate. In regard to personnel preparation, while both parents and administrators expressed concern over low levels of implementation, it was clear that parents had little confidence in the training of teachers and other support professionals. Certainly these perceptions are valid, and perhaps more concerning, they appear to reflect a reality of a lack of qualified ASD personnel in schools (Morrier, Hess, \& Heflin, 2011; Schwartz \& Drager, 2008). Without a doubt, there still exists a substantial need for increased teacher preparation; however this problem is complicated by multiple factors, including a general lack of consensus on effective training models.

Evidence for an ideal curriculum or intervention appropriate for all students with ASD has yet to be provided (McKenna, 2007; National Research Council, 2001). Yet, there are several reviews that highlight agreed-upon essential programming elements for students of all ages with ASD (Dawson \& Osterling, 1997; Hurth, Shaw, Izeman, Whaley, \& Rogers, 1999; National Research Council, 2001). These elements have been synthesized by lovannone, Dunlap, Huber, and Kincaid (2003) into six components:

1. individualized supports and services for students and families,

2. systematic instruction,

3. comprehensive and/or structured environments,

4. specialized curriculum content,

5. functional approach to behavior problems, and

6. family involvement. (p. 153)

With these components in mind, a relatively recent study surveyed IHEs in an effort to ascertain the topics included in ASD coursework and the depth to which they were addressed (Barnhill, Polloway, \& Sumutka, 2011). Faculty members at 87 IHEs in 34 states responded to surveys. Researchers found that a large number of IHEs are offering preparation programs related to ASD, yet there is substantial variability in the nature of these programs. The authors concluded that this variability could be due to the fact that relatively few states offer a licensure program in the area of ASD, which leaves IHEs without much guidance in terms of development of programs and related competencies. Further, certification/endorsements are determined by state agencies, 
and IHEs can only offer certification/endorsements allowed by their state, again leaving most IHEs on their own for developing programs for training in ASD. Despite the variability in program development and competencies for ASD, a clear majority of the opportunities for training included a "hands-on" experience component, which comprised direct work with individuals with ASD. Several other commonalities were noted in emphases reflected in programs such as characteristics, causes, definitions, assessment procedures, functional behavioral assessment, behavioral intervention, and positive behavioral supports. Less common were more specific types of interventions (e.g., discrete trial training, pivotal response training, etc.) and family involvement. As many of the programs surveyed were new and many of the IHEs reported "plans" to create programs in the near future, this appears to be a burgeoning area with the likelihood of changes and developments up ahead.

There is considerable effort under way to provide guidelines and recommendations to IHEs and other stakeholders concerned with the education of students who have ASD. The Nationals Standards Project (National Autism Center, 2009) is a large-scale report providing critical information about which treatments have been shown to be effective for individuals with ASD, and will likely have an impact on future program development and areas of focus within IHEs. Additionally, the Council for Exceptional Children (2009) in collaboration with the Autism Society of America have published professional competencies for teaching students with ASD.

The National Standards Project identified 11 types of interventions, which are supported by scientific evidence as being effective instructional strategies for students with ASD. However, preparing special education teachers to be effective interventionists in that many treatments may be untenable, and finding master teachers knowledgeable in all treatments near to impossible. The results of a recent survey shed some interesting light on how pre-service teachers gain knowledge of the different treatments (Porter, Todd, \& Regalado, 2013). Treatments with clearly defined observable steps (e.g., modeling, schedule-based, and self-management interventions) received higher observation and practice scores than treatments that are embedded in instruction and perhaps difficult to readily observe (PRT, joint attention). Perhaps the emphasis of personnel preparation need not be so focused on intervention training and specialization, but also on components that include engaging key stakeholderssuch as families. Additional topics in the curriculum such as understanding family backgrounds, concepts of caring, parent and sibling stress, and coping mechanisms will provide the student teacher with tools for engaging parents in their classroom. 
Teachers and stakeholders agree that teacher-parent partnerships enhance the educational experience for students; however this topic is generally not addressed in-depth in teacher preparation programs. This leads to two problems: First, teachers are not equipped with strategies and communication skills to engage with parents. Secondly, the fact that the topic was not addressed in university, or professional development, sends the message that it is not important (Unal \& Unal, 2014). Several researchers created a questionnaire and interview guide to evaluate pre- and in-service teachers' perspectives on preparation in parental involvement strategies, and explored their opinions on what they felt teacher preparation programs should offer in this area (Unal \& Unal, 2014). The questionnaire was given to 223 pre- and in-service teachers at five IHEs in years 1, 2, and 3 of the teacher preparation programs. Overall, teachers felt they had received little preparation for parent involvement. Over $65 \%$ of pre-service teachers felt that a course in parental involvement would be helpful. As the preservice teachers completed fieldwork and realized the importance of teacher-parent relationships, they expressed less satisfaction with the amount and type of knowledge presented in their programs (Unal \& Unal, 2014). The importance of effective strategies was highlighted in an in-depth study of teacher practices at inner-city schools in a major city. Results of the qualitative study reported that teacher preparation programs that do address parent involvement strategies, often fashioned on Epstein's model, can bring about a change in teachers' perception of parents and consequently increase parental involvement (Lewis, Kim, \& Bey, 2011).

The above suggestions and resources can provide personnel preparation programs with comprehensive guidance for training educators who will be responsible for teaching students with ASD, which will ultimately benefit both individuals with ASD and their families.

\section{Bridging the Gap: Teacher-Parent Partnerships}

Parents approach schools with anticipation and hope, often very knowledgeable about current practices, which they may have been implementing in the home. Unfortunately, tension can arise between parental expectations and the realities of the classroom, or from a teacher's perspective of a parent's skills and effectiveness. Though teacher-parent partnerships are increasingly realized as vital to student success (Abel, 2012) and can benefit all parties (Epstein \& Dauber, 1991), they are seldom fully realized, as both parties face distinct barriers. Parents may not know what volunteer opportunities are available, may not have time to volunteer due to younger children at home, may work during school hours, or may lack confidence in the educational process (Margaritoiu \& Eftimie, 2011). Teachers have reported barriers which include: 
not knowing effective strategies to engage parents; not having enough time after completing all their other tasks to address parent engagement; and not realizing the value of family participation.

However, parents need to be involved with their child's school. Miedel and Reynolds (1999) surveyed parents and interviewed teachers at an early intervention program for at-risk preschoolers in a large city. They found a strong relationship between a parent's involvement in school activities, reading achievement, and the child's likelihood of being retained in a special education classroom through Grade 8 . The more activities the parents were involved in the less likely the child was to be retained in special education. Activities included helping on field trips and in the classroom, attending school meetings and parent-teacher conferences, as well as having a home visit by the teacher. The authors of this study emphasized that teachers in the schools involved in the study actively invited the parents to participate in a variety of school-related activities. The rate of parent involvement was high; this is a good example of a successful parent involvement program.

Unfortunately, teacher-parent communication and involvement is not generally addressed in teacher preparation programs (Unal \& Unal, 2014). Consequently, teachers often feel ill prepared to collaborate with parents or simply do not value or seek out such a relationship. Parent involvement can take many dimensions and should not be limited to once-a-year IEP meetings. Epstein (1991) conceptualized parental involvement as having six components: (1) participating in parenting, (2) communicating with teachers and schools, (3) volunteering at school, (4) helping children learn at home, (5) participating in decision making at school, and (6) collaborating with the community. Participating in parenting refers to creating a home environment that supports children as students. Teachers who are equipped with strategies that target a range of components will have an easier time promoting parent involvement at many different levels. Many teachers may start with the second component, communication, which has been found essential in student success.

Teacher-parent communication can be perceived as a challenge by teachers and pre-service teachers (Busby, Ingram, Bowron, Olive, \& Lyons, 2012). During interviews, teachers and pre-service teachers shared their concern about the amount of time commitment necessary in establishing teacher-parent communication (Busby et al., 2012). Though valuing parent collaboration, teachers were concerned about the additional time commitment with all of their other responsibilities. The quality of teacher-parent communication may also be an obstacle. It tends to be uni-directional as the teacher often sends information to the family in the way of notices or reports 
without expectation of a response. An emphasis on two-way communication should be highlighted to attain best results (Abel, 2012).

Teacher-parent communication exchanges can also be complicated with differences in perspectives. A recent survey of school-family relationships found that "there is a real need for training teachers about how to relate to parents" (Margaritoiu \& Eftimie, 2011, p. 46) and that teachers and parents have very different perceptions of barriers to parental involvement. The results of a survey to teachers and families found that secondary school teachers felt low levels of parent involvement were due to a lack of parent responsibility, indifference, low levels of parent education, attitudes of superiority, fear of confrontation with the teacher, or health problems. The parents' answers to the same question revealed a different perspective. They cited lack of time being the primary reason for low involvement followed by lack of confidence in the school system, hostile attitude, large number of family members, lack of information, and health problems. With differing perceptions of the same issue it is not surprising that effective communication and strategies to remedy the problem were not readily forthcoming.

Recent studies have shown that teachers of children with behavioral challenges often identify problems in the home to be the cause; more specifically, mothers are often thought to be responsible for their child's emotional and social difficulties (Broomhead, 2013). References to "dysfunctional family," "ineffective parenting," or a "lack of discipline" are used frequently in reference to families. Not surprisingly, parents often state they feel that professionals blame them for their child's behavior. Therefore, communication between the two parties can become strained if one party feels blamed by the other.

Teachers may also not completely understand the stress of the family. Research has demonstrated that parents of children with ASD experience higher levels of stress and lower levels of well-being than parents of children without ASD or any other type of disability (Baker-Ericzen, Brookman-Frazer, \& Stahmer, 2005). In particular, the parents experience unique challenges associated with ASD such as frustration with communication, over-stimulation, and challenging behavior (Baker, Blacher, Crnic, \& Edelbrock, 2002). In addition, a higher number of parents of children with ASD exhibit a broader autism phenotype (BAP), which includes subtle impairments in social reciprocity and communication, increases in restricted/repetitive interests and behaviors, and more psychiatric symptoms (Piven, 2001) than the general population. Therefore, some parents may have limited resources available to cope with the demands of a child with ASD. These deficits also make it difficult to interact effectively with teachers and other professionals involved in their child's life. 
Parents of children with ASD cope with stress in a variety of ways, some more effectively than others. Two researchers recently studied the effect of 12 coping strategies used by parents of children with ASD (Pottie \& Ingram, 2008). Certain coping responses were found to be associated with positive outcomes. However, other coping strategies frequently used by parents of children with ASD led to negative outcomes. Certainly, personality of the parent and context of the event influenced the effectiveness of each strategy. That withstanding, certain strategies proved more effective in reducing parent stress and improving well-being. Table 1 shows a list of the coping strategies and outcomes. Teachers can use this table to recognize if a parent is using an ineffective coping strategy, and at that point the teacher can model an effective strategy. Instead of a breakdown in parent-teacher interaction this approach can lead to better communication. Additionally, the teacher can recognize that at this point in time the parent is experiencing a great deal of stress and may not be able to use a better strategy, therefore it may not be a good time to exchange a large amount of information.

\section{Table 1}

Recognizing Strategies Commonly Used by Parents of Children With ASD That Increase or Decrease Well-Being (Pottie \& Ingram, 2008)

\begin{tabular}{|l|l|l|}
\hline STRATEGY & $\begin{array}{l}\text { IMPROVES WELL-BEING } \\
\text { AND DECREASES STRESS }\end{array}$ & $\begin{array}{l}\text { DECREASES } \\
\text { WELL-BEING }\end{array}$ \\
\hline $\begin{array}{l}\text { Problem Focused: taking action to deal } \\
\text { with a difficult or stressful situation in a } \\
\text { concrete or organized manner }\end{array}$ & & \\
\hline $\begin{array}{l}\text { Social Support: reaching out to others } \\
\text { for emotional and/or practical/concrete } \\
\text { assistance }\end{array}$ & & \\
\hline $\begin{array}{l}\text { Escape or Avoidance: removing or } \\
\text { disengaging oneself from the stressful } \\
\text { situation, or refusing to accept the reality } \\
\text { of the situation }\end{array}$ & & \\
\hline $\begin{array}{l}\text { Distraction: dealing with a stressful } \\
\text { situation by engaging in an alternative } \\
\text { pleasurable activity or self-care }\end{array}$ & & \\
\hline $\begin{array}{l}\text { Blaming: actions that involve frustration, } \\
\text { anger, blaming, or passive aggression }\end{array}$ & & \\
\hline $\begin{array}{l}\text { Positive reframing: changing one's } \\
\text { view of a stressful situation in order to } \\
\text { see it in a positive/more tolerable light }\end{array}$ & & \\
\hline
\end{tabular}


Table 1

Recognizing Strategies Commonly Used by Parents of Children With ASD That Increase or Decrease Well-Being (Pottie \& Ingram, 2008) (cont.)

\begin{tabular}{|l|l|l|}
\hline STRATEGY & $\begin{array}{l}\text { IMPROVES WELL-BEING } \\
\text { AND DECREASES STRESS }\end{array}$ & $\begin{array}{l}\text { DECREASES } \\
\text { WELL-BEING }\end{array}$ \\
\hline $\begin{array}{l}\text { Worrying: constant or frequent thinking } \\
\text { about the negative or difficult aspects of } \\
\text { a stressful situation }\end{array}$ & & \\
\hline $\begin{array}{l}\text { Emotional Regulation: controlling or } \\
\text { expressing emotional distress in a way } \\
\text { that is constructive or appropriate for the } \\
\text { situation }\end{array}$ & & \\
\hline $\begin{array}{l}\text { Withdrawal: staying away from certain } \\
\text { people or preventing others from } \\
\text { knowing about the stressful situation or } \\
\text { its emotional effects }\end{array}$ & & \\
\hline $\begin{array}{l}\text { Compromise: working out a } \\
\text { compromise between the priorities/ } \\
\text { needs of the individual and the limits of } \\
\text { the stressful situation }\end{array}$ & & \\
\hline $\begin{array}{l}\text { Helplessness: giving up or surrendering } \\
\text { control because the stressor was/is } \\
\text { overwhelming }\end{array}$ & & \\
\hline
\end{tabular}

Successful programs require ongoing communication between parents and teachers. Parents seek out educators that want family involvement and are willing to communicate with them on a regular basis. When teachers see parents from an asset perspective (Abel, 2012), they are more open to working on two-way communication and doing background work to supply parents with the resources required to teach skills at home. Accordingly, teachers with positive attitudes regarding parental involvement may have more success engaging "hard-to-reach" parents (Abel, 2012).

\section{Conclusion}

One in every 68 children is currently diagnosed with an autism spectrum disorder (Frieden et al., 2014). While changes in teacher preparation programs are occurring, it appears they are not keeping up with demands of the students and families. Teacher-parent communication and collaboration offers important support for 
students with ASD. Teacher preparation programs and school administrators should incorporate course work and workshops to help teachers develop skills and strategies to communicate with, and involve parents in, their child's education. These programs should also create opportunity for teachers' development in understanding the needs and stress encountered by families of students on the autism spectrum. Recent studies in which pre-service teachers, teachers, and parents were surveyed and interviewed can be summarized into several recommendations for teacher preparation programs and school administrators. At the top of the list is having the opportunity to meet and interact with parents and family members of children with disabilities. To that point, some pre-service teachers suggested a course on parental involvement (Busby et al., 2012). Next, workshops on 1) strategies to increase communication and parental involvement, 2) family concepts including parent efficacy, 3) specific information on successful parental involvement programs, and 4) empirically validated and best practices for instruction including children with ASD were also suggested (Busby et al., 2012; Hoover-Dempsey Walker, Jones, \& Reed, 2002; Unal \& Unal, 2014). Additionally, teachers in training should have the opportunity to observe parental involvement in the classroom and schools, and witness effective teacher-parent communication (Unal \& Unal, 2014). Taken together, these training and professional development strategies will provide a strong basis on which to build teacher-parent partnerships-and which will ultimately improve the education of students with ASD.

\section{Final Note From Parent-Teacher}

No one can raise a child with diverse learning skills alone. My son's growth depended on close, consistent communication with his teachers throughout his school years. I learned how to follow up on what lan learned at school. His teachers learned what challenges our family faced. The more his teachers and I understood each other's perspectives, the more we could work together as a team.

\section{References}

Abel, Y. (2012). Process into products: Supporting teachers to engage parents. Education and Urban Society, 46, 181-191. doi:10.1177/0013124512446307
Baker, B., Blacher, J., Crnic, K., \& Edlebrock, C. (2007). Behavior problems and parenting stress in families of three-year old children with and without developmental delays. American Journal of Mental Retardation, 107, 433-444. 
Baker-Ericzen, M., Brookman-Frazee, L., \& Stahmer, A. (2005). Stress levels and adaptability in parents of toddlers with and without autism spectrum disorder. Research \& Practice for Person With Severe Disabilities, 30, 194-204.

Barnhill, G. P., Polloway, E. A., \& Sumutka, B. M. (2011). A survey of personnel preparation practices in autism spectrum disorders. Focus on Autism \& Other Developmental Disabilities, 26(2), 75-86. doi:10.1177/1088357610378292

Broomhead, K. (2013). Blame, guilt and the need for 'labels'; insights from parents of children with special educational needs and educational practitioners. British Journal of Special Education, 40(1), 14-21.

Busby, R., Ingram, R., Bowron, R., Olive, J., \& Lyons, B. (2012). Teaching elementary children with autism: Addressing teacher challenges and preparation needs. Rural Educator, winter, 27-35.

Council for Exceptional Children. (2009). What every special educator must know: Ethics, standards, and guidelines (6th ed. rev.). Arlington, VA: Author.

Dawson, G., \& Osterling, J. (1997). Early intervention in autism. In M. Guralnick (Ed.), The effectiveness of early intervention (pp. 307-326). Baltimore, MD: Brookes.

Epstein, J. L. (1991). Effect on student achievement of teachers' practices of parent involvement. Advances in Reading and Language Research, 5, 261-276.

Epstein, J. L., \& Dauber, S., L. (1991). School programs and teacher practices of parent involvement in inner-city elementary and middle schools. The Elementary School Journal, 91, 289-305.

Frieden, T. R., Joffe, H. O., Cono, J., Richards, C.L., \& lademarco, M. F. (2014). Prevalence of Autism Spectrum Disorder Among Children Aged 8 Years - Autism and Developmental Disabilities Monitoring Network, 11 Sites, United States, 2010. MMWR, SSO2, 1-21.

Hoover-Dempsey, K. V., Walker, J. M., Jones, K. P., \& Reed, R. P. (2002). Teachers involving parents (TIP): Results of an in-service teacher education program for enhancing parental involvement. Teaching and Teacher Education, 18, 843-867.
Hurth, J., Shaw, E., Izeman, S. G., Whaley, K., \& Rogers, S. J. (1999). Areas of agreement about effective practices among programs serving young children with autism spectrum disorders. Infants \& Young Children: An Interdisciplinary Journal of Special Care Practices, 12(2), 17.

Hutchinson, N. (2006). Inclusion of exceptional learners in Canadian schools: A practical handbook for teachers. Toronto, Ontario, Canada: Pearson Education, Inc.

IDEA. (2004). Individuals With Disabilities Education Improvement Act of 2004.

Institute of Education Sciences, U.S. Department of Education. (2011). National Assessment of IDEA Overview; IDEA National Assessment Implementation Study Executive Summary and Report (Indexes; Offices). Retrieved from: http://ies.ed.gov/ncee/pubs/20114026/

lovannone, R., Dunlap, G., Huber, H., \& Kincaid, D. (2003). Effective educational practices for students with autism spectrum disorders. Focus on Autism \& Other Developmental Disabilities, 18(3), 150-165.

Kohen, D., Uppal, S., Khan, S., \& Visentin, L. (2006). Access and barriers to educational services for Canadian children with disabilities. Retrieved from: http://www.ccl-cca.ca/CCL/Reports/ OtherReports/201009KohenUppalKhanVise ntinAccessBarriers.html

Leblanc, L., Richardson, W., \& Burns, K. A. (2009). Autism spectrum disorder and the inclusive classroom: Effective training to enhance knowledge of ASD and evidence-based practices. Teacher Education and Special Education, 32(2), 166-179.

Lewis, L. L., Kim, Y. A., \& Bey, J. A. (2011). Teaching practices and strategies to involve inner-city parents at home and in the school. Teaching and Teacher Education, 27, 221-234.

Margaritoiu, A., \& Eftimie, S. (2011). Some issues concerning school-family partnerships. Procedia Social and Behavioral Sciences, 11, 42-46.

McKenna, K. (2007). Confronting the autism epidemic. Harvard Education Letter, 23(5), 1-6.

Miedel, W. T., \& Reynolds, A. J. (1999). Parent involvement in early intervention for disadvantaged children: Does it matter? Journal of School Psychology, 37, 379-402. 
Morrier, M. J., Hess, K. L., \& Heflin, L. J. (2011). Teacher training for implementation of teaching strategies for students with autism spectrum disorders. Teacher Education and Special Education: The Journal of the Teacher Education Division of the Council for Exceptional Children, 34(2), 119-132. doi:10.1177/0888406410376660

National Autism Center. (2009). National Standards Report: The National Standards Project - addressing the need for evidencebased practice guidelines for autism spectrum disorders. Randolph, MA: Author. Retrieved from: http://www.nationalautismcenter.org/ pdf/NAC\%20Standards\%20Report.pdf

National Research Council. (2001). Educating Children With Autism. Committee on Educational Interventions for Children With Autism. Division of Behavioral and Social Sciences and Education. Washington, DC: National Academy Press. Retrieved from: http://proxy.library.oregonstate.edu/ login?url=http://search.ebscohost.com/ login.aspx?direct=true $\& \mathrm{db}=$ eric $\& A N=E D 461$ 956\&site=ehost-live

Piven, J. (2001). The Broad Autism Phenotype: A complementary strategy for molecular genetic studies of autism. American Journal of Medical Genetics, 105, 34-35.

Porter, S., Todd, T., \& Regalado, M. (2013). Validation of the California Preparedness to teach students with Autism (CAPTSA): Survey for Pre-service special education teachers. International Journal of Cross-Disciplinary Subjects in Education, 4, 1456-1478.

Pottie, C. G., \& Ingram, K. M. (2008). Daily stress, coping, and well-being in parents of children with autism: A multilevel modeling approach. Journal of Family Psychology, 22, 855-864.

Schopler, E., \& Olley, J. G. (1980). Public School Programming for Autistic Children. Exceptional Children, 46(6), 461-463.

Schwartz, H., \& Drager, K. D. R. (2008). Training and knowledge in autism among speechlanguage pathologists: A survey. Language, Speech, and Hearing Services in Schools, 39(1), 66-77.
Simpson, R. L. (1995). Children and youth with autism in an age of reform: A perspective on current issues. Behavioral Disorders, 21(1), 7-20.

Simpson, R. L. (2003). Policy-related research issues and perspectives. Focus on Autism \& Other Developmental Disabilities, 18(3), 192-196.

Simpson, R. L. (2004). Finding effective intervention and personnel preparation practices for students with autism spectrum disorders. Exceptional Children, 70(2), 135-144. doi:10.1177/001440290407000201

Tincani, M., Cucchiarra, M., Thurman, S., Snyder, M., \& McCarthy, C. (2014). Evaluating NRC's recommendations for educating children with autism a decade later. Child \& Youth Care Forum, 43(3), 315-337. doi:10.1007/ s10566-013-9240-z

Unal, Z., \& Unal, A. (2014). Perspectives of preservice and in-service teachers on their preparation to work with parents in elementary classrooms. The Educational Forum, 78, 112-126. doi:10.1080/00131725.2013.878425

U.S. Department of Education Institute of Education Sciences National Center for Education Statistics. (2013). Percent distribution of students 6 to 21 years old served under Individuals with Disabilities Education Act (IDEA), Part $B$, by educational environment and type of disability: Selected years, fall 1989 through fall 2011 (No. Table 204.60). Retrieved from: http://nces.ed.gov/programs/digest/ d13/tables/dt13_204.60.asp

U.S. Department of Education, National Center for Education Statistics. (2013). Digest of Education Statistics, 2012 (Table 48). Retrieved from: http://nces.ed.gov/fastfacts/display. asp?id $=64$

Winzer, M. (2007). Children with exceptionalities in Canadian schools. Toronto, Ontario, Canada: Pearson Education, Inc. 


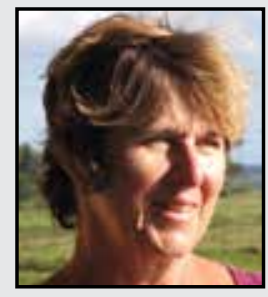

Teri Todd is an Assistant Professor in the Department of Kinesiology at California State University, Northridge. Her primary research interests center around physical activity and individuals with developmental disabilities, particularly those on the autism spectrum. Teri is the Director of Clinical Operations at the Center of Achievement Through Adapted Physical Activity at CSUN, teaches classes, and is developing adapted physical activity programs for children with developmental disabilities. As a parent of a son with Autism Spectrum Disorder she realizes first-hand how complicated, but essential, family support is for individuals with developmental disabilities.

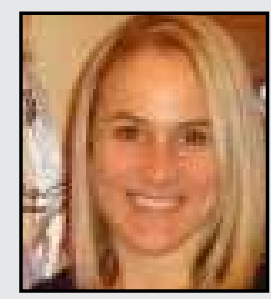

Jennifer Beamer is an Instructor at Oregon State University in Corvallis, Oregon. Her primary research interests revolve around the preparation of physical educators and physical activity professionals for working with people who have disabilities. Her work at there includes teaching physical education teacher education courses, advising students, and serving as co-director for the IMPACT program-a physical activity program for children and youth with disabilities. The program acts as a service learning experience for students at OSU, as well as a valuable resource for nearly 100 families in the surrounding communities in need of physical activity opportunities.

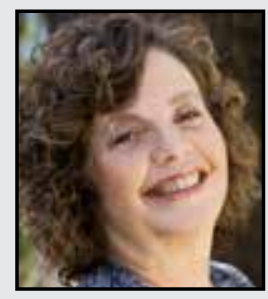

Joan Goodreau is the parent of an adult son with Autism Spectrum Disorder. Her experience as a Special Education teacher and Program Specialist gives her both a professional and personal perspective. She has published numerous articles, stories, and poems in journals and anthologies in Canada and the United States. Her recent books are Strangers Together: How My Son's Autism Changed My Life and Poems From the Spectrum: How My Son's Autism Changed My Family. 